This is the post print version of the article, which has been published in Journal of knowledge management. 2018, 22(1), 219-234. http://dx.doi.org/10.1108/JKM-06-2017-0232 .

Laihonen Harri, Mäntylä Sari

Dhis document has been downloaded from TamPub uta.fi The Institutional Repository of University of Tampere

\title{
STRATEGIC KNOWLEDGE MANAGEMENT AND EVOLVING LOCAL GOVERNMENT
}

\begin{abstract}
Purpose: The characteristics of new public management and new public governance are well known, but their impact on managerial knowledge needs and the implementation of knowledge management in local government remains unclear. This paper elaborates the key elements of a public organization's knowledge strategy and shows how knowledge management can support public management.
\end{abstract}

Design/Methodology/Approach: A case study on the application of an action research process was conducted to study how the City of Tampere in Finland aimed to overcome challenges in utilizing performance information by applying the ideas of knowledge management.

Findings: The study suggests that a holistic knowledge management strategy promotes the use of performance information by providing a systematic management framework for gathering and utilizing the information.

Practical implications: Four factors appear critical for strategic knowledge management in local government. First, it should be driven by the city's strategy. Second, it should be carefully integrated into the general management system. Third, clear processes and responsibilities for refining the data are needed. Fourth, the quality of the data must be guaranteed. The results also emphasize the roles of management culture and continuous performance dialogue.

Originality/Value: This paper makes two contributions. First, it extends the analysis of a knowledge management strategy to public management and, second, it provides a practical illustration of the development process, where knowledge was put into prime focus in developing public management.

Keywords: knowledge strategy, knowledge management, public sector, public management, local government, case study 


\section{Introduction}

This paper presents a managerial perspective on the ongoing transformation from new public management (NPM) to new public governance (NPG) in local government and studies the role of strategic knowledge management in governing the change in organizations' knowledge processes. Despite the abundant literature on NPM and NPG (e.g., Billis, 2010; Hood, 1995; Osborne, 2006; Pollitt and Summa, 1997; Pollitt, van Thiel, and Homburg, 2007; Sanderson, 2001; van Helden, Johnsen, and Vakkuri, 2008), a research gap exists regarding their impact on managerial knowledge needs. The aim of this paper is to bridge this gap by applying a qualitative case study approach and answering the following research question: What are the key elements of strategic knowledge management when a local government organization is undergoing a transformation from NPM to NPG?

The knowledge management literature proposes two ways of seeing the strategic role of knowledge in organizations. The wider perspective takes knowledge-based value creation into consideration and aims at understanding how knowledge as a strategic resource makes a difference in a competitive sense (Grant, 1996; Spender, 1996). The narrower approach focuses on decision-making and reflects an attempt to rationalize organizations' decision-making processes. Although the wider perspective may be a more appropriate approach in the public sector, where political and administrative interests meet, it seems that, at least in Finland, the dominant approach is actually the narrower approach. This is illustrated by a program initiated by the government of former Prime Minister Jyrki Katainen. In 2011 it was stated that "Productivity in the public sector will be boosted through better utilisation of business intelligence, more compatible information systems, and by bringing together information management data and procurement resources data in public administration. Shared use of public administration information will be facilitated” (Valtioneuvosto, 2011, 137-138). As this quotation indicates, there was a strong political will to increase the use of advanced knowledge management approaches and to improve the decision-making capacity and performance of the Finnish public sector.

By following the dominant public discussion in Finland, this paper first illustrates how the City of Tampere as one of the forerunners in the area has responded to the political call and improved its decision-making. The City of Tampere has also implemented one of the most radical reforms in Finnish municipal administration so far (see section 3.1), which makes it an interesting case study. After the empirical investigation, the main contribution of the paper will arise from a discussion of the weaknesses inherent in the dominant narrow perspective. This 
approach easily over-rationalizes public decision-making processes and does not take full advantage of the knowledge management approach. Indeed, the paper argues that major systemic changes necessitate strategic knowledge management in public organizations (Anttiroiko, 2008) and a thorough analysis of the underlying value creation processes, which calls for interdisciplinary dialogue. The paper therefore contributes to the discussion on public knowledge management by providing empirical evidence of timely discussion in local government in Finland. Finland provides an interesting research environment in knowledge issues because of its highly educated population, efficient public sector and stable legal and political systems. In addition, the consensus seeking, communicative nature of Finnish society provides a good opportunity to study the role of knowledge management in decision-making processes.

The remainder of the paper is organized as follows. Section 2 reviews the relevant literature. Section 3 presents the conceptual framework for the empirical examination and describes the research design. Section 4 reports the action research process carried out in the City of Tampere. Section 5 presents the analysis of the empirical process and identifies the key elements of strategic knowledge management during the transformation of the local government from NPM to NPG. Section 6 concludes the discussion and suggests directions for further research.

\section{Literature review}

\subsection{Challenges of Knowledge Management in Local Government}

According to the knowledge-based view, knowledge is a critical input in production and a primary source of value (Grant, 1996; Spender, 1996). Knowledge management refers to identifying and leveraging the collective knowledge in an organization to help the organization compete (von Krogh, 1998). It involves processes such as creating, storing, transferring, and applying knowledge (Alavi and Leidner, 2001). Most importantly, knowledge management is aimed at improving an organization’s overall performance (Kalling, 2003).

The public management literature recognizes various uses of performance information (e.g., Behn, 2003; Hammerschmid, Van de Walle, and Stimac, 2013; Moynihan and Pandey, 2010) and discusses factors affecting either its use or nonuse (e.g., Moynihan and Ingraham, 2004; Taylor, 2011). Scholars have argued that public organizations use performance information mainly for advocacy and lack the ability to engage in goal-based learning (Moynihan, 2005; 2008). Some research has also shown that the instrumental use of performance information 
(i.e., a direct link between measurement and judgment) is rare (e.g., Pollitt, 2006; Van Dooren and Van de Walle, 2008). The availability of information is considered to be an important performance driver (Moynihan and Pandey, 2010), but management practice seems to lack the frameworks and practices that enable and reinforce interpretative processes and organizational learning based on performance information (Moynihan, 2008; Rashman, Withers, and Hartley, 2009).

One possible reason for the failure of public organizations to utilize performance information relates to the evolution of public management. Public organizations have been managed with a hierarchical chain of command (Hartley, 2005; Osborne, 2006), where information needs are chiefly related to cost control and the measurement of service outputs (i.e., units of service usage) (Jääskeläinen and Laihonen, 2014). More recently, the emphasis has shifted to services and their long-term value (Hartley, 2005; Jääskeläinen and Laihonen, 2014; Pollitt, van Thiel, and Homburg, 2007; Sanderson, 2001). The spread of the network society and the ideas of a more pluralist model of governance have further increased the complexity of public management and the diversity of the management information needed (Hartley, 2005; Osborne, 2006). The focus of management has shifted from intraorganizational management and mere input-output discussions to inter-organizational governance and interest in service outcomes.

Horizontal cooperation, network relations, and an increasing reliance on partnerships are changing the requirements for performance information and knowledge management in the public sector (Haveri et al., 2009; Klijn, 2008; Peters, 2011; Salamon, 2002). In practice, this means that the existing performance information must be complemented at least by information on the success of the inter-organizational cooperation as well as the effectiveness of various service providers and the service system as a whole (Laihonen, Jääskeläinen, and Pekkola, 2014; Lönnqvist and Laihonen, 2012). This adds to the ambiguity of public management (Vakkuri, 2010), gives rise to cultural tensions (McGuire, 2006), and casts a certain amount of doubt on the ability of an individual manager to master the complexity of local government.

In addition, the literature has recognized several more specific obstacles to the application of knowledge management in the public sector. Edge (2005) states that public knowledge management has been approached mainly from the technological perspective (e.g., BeynonDavies and Martin, 2004; King and Cotterill, 2007) and by concentrating predominantly on certain public services, such as the police (Luen and Al-Hawamdeh, 2001), education (Edge, 2005; Syysnummi and Laihonen, 2014), or healthcare (Laihonen, 2012; 2015; van Beveren, 2003). Furthermore, cultural challenges are related to resistance to change and hoarding of 
knowledge (Sveiby and Simons, 2002). Finally, incompatible information systems, hierarchical and bureaucratic organizations, and unarticulated managerial information needs pose challenges (Behn, 2003; Liebowitz and Chen, 2003; Vakkuri. 2010).

\subsection{Strategic Knowledge Management}

Knowledge strategy defines valuable knowledge and the processes necessary for its acquisition, sharing, and utilization (cf. Hansen, Nohria, and Tierney, 1999; Laihonen, Lönnqvist, and Metsälä, 2015; Zack, 1999). Here, the specific focus is on performance information and decision support; therefore, we use the narrower concept of "knowledge management strategy." This framing is intended to introduce new perceptions into the argument that public organizations suffer from the inadequate use of performance information (e.g., Hammerschmid, Van de Walle, and Stimac, 2013; Moynihan and Pandey, 2010; Pollitt, 2006; Taylor, 2011; Van Dooren and Van de Walle, 2008).

A knowledge management strategy determines which knowledge resources are valuable, unique, and indispensable, and how those resources support an organization's business strategy (Earl 2001; Hansen, Nohria, and Tierney, 1999; Zack, 1999). There is evidence from the private sector of a correlation between higher levels of knowledge management maturity and longterm sustainable growth (Salojärvi, Furu, and Sveiby, 2005) and some indications of the effects of certain knowledge management strategies on organizational performance (e.g., Choi and Lee, 2003; Choi, Poon, and Davis, 2008; Hitt, Ireland, and Lee, 2000; Yang, 2010).

The knowledge management literature provides several guidelines for developing, choosing, and implementing a knowledge management strategy (Earl, 2001; Haggie and Kingston, 2003; Soliman and Spooner, 2000; Zack, 1999). Earl (2001) and Zack (1999) focus on recognizing performance gaps in discovering where an organization's capabilities do not suffice for the strategy envisaged. The next step in determining a knowledge management strategy is to ask how knowledge can make a difference in filling these performance gaps. According to Zack (1999), every strategic decision has a profound influence on knowledge, skills, and core competencies. Analogously, the knowledge that an organization actually has at its disposal limits the ways in which it can compete. One of the most important tenets in the literature is that the identification and selection of knowledge management initiatives and tools should always be a derivative of the business strategy (Earl, 2001; Hansen, Nohria, and Tierney, 1999; Zack, 1999).

In local government or in public management more generally, the fundamental question is thus: How can knowledge management support ongoing changes in public service provision 
and in particular the management of public organizations? The literature provides a number of theoretical models elaborating the characteristics of NPM and NPG models (e.g., Nemec, 2013; Osborne, 2006) and proposes guidelines for composing knowledge management strategies (e.g., Earl, 2001; Zack, 1999). However, what seems to be missing is a more focused analysis of knowledge management when the previously closed system opens up and the consequent transparency, networking, and citizen participation necessitate a thorough strategic shift. The empirical examination in the present study focused on how the City of Tampere aimed to improve its knowledge management practices and the use of performance information during its ongoing transformation from an internally focused bureaucracy to a customer- and serviceoriented modern city.

\subsection{Framework of the Analysis}

The literature review described the ongoing shift in public management. This change has created new information needs, and it affects knowledge processes in many ways. Although there is ample literature on the management ideal to which organizations aspire, significantly less is known about the change process and its implications for managerial knowledge needs. As hierarchical chains of command break down and the spread of the network society calls for horizontal cooperation, this necessitates a significant shift in organizations' knowledge management practices and changes the requirements for performance information, as noted in the literature review. This has been acknowledged in the performance management literature, which focuses increasingly on interpretative processes and organizational learning (Moynihan and Landuyt, 2009; Rashman et al., 2009) and highlights the social nature of performance management (Bititci et al., 2012). However, no research has been carried out specifically on the information and knowledge processes underlying the shift from centralized and vertical management practices to decentralized and horizontal ones.

The empirical examination was guided by the core components of a knowledge strategy (Zack, 1999): business strategy, performance gap, knowledge gap, and knowledge initiatives. This fourfold framework was used to structure the action research process carried out in the City of Tampere. Section 3 will follow the same structure in reporting the transformation process towards an NPG model from the knowledge management perspective. 


\section{Research design}

\subsection{Context of the Empirical Study}

International comparison has shown that Finnish local governments have had a highly significant role because the municipalities themselves organize and produce a large proportion of public services. Central government controls the equality of service provision but local governments in Finland enjoy extensive autonomy. In addition, financially, 80 per cent of their funding comes from local sources. The Finnish local government structure is currently undergoing rapid change; municipalities are merging, and according to the most recent reform, there will be 18 autonomous regions in the country charged with providing healthcare and social services in their respective areas (Ministry of Finance, 2016). Then public administration in Finland will be organized into three tiers - central government, autonomous regions, and local governments. This reform will make the provision of healthcare and social services more versatile, which in turn will impose stringent requirements on inter-organizational knowledge processes.

Tampere is a city in southern Finland. It is the most populous inland city in the Nordic countries, with a population of 223,004, making it the second largest urban area and third most populous municipality in Finland. The city is also the largest employer in the area $(15,152$ employees), and annual service expenditures amount to $€ 1,380$ million (City of Tampere, 2014). Welfare services (healthcare, social services, and education) comprise the largest sector (76 per cent of employees), and 59 per cent of these services are actually produced by the city.

At the beginning of 2007, Tampere implemented an administrative reform that was unprecedented in the context of Finnish municipalities. The reform introduced the multipleprovider model in all municipal operations (separating the purchaser and provider roles). In Finland, many municipalities have sought new approaches to delivering services in cooperation with private companies and third-sector organizations. As a result, municipalities have become increasingly dependent on private and third-sector actors in pursuit of their objectives. In Tampere, the management reform relied heavily on NPM (public-private business logic, customer orientation, management by results) but was also intended to overcome the acknowledged weaknesses of NPM (Hakari, 2013). According to Hakari (2013), the model has subsequently been developed toward NPG by promoting local democracy, citizen participation, networks, and transparency in government.

In conjunction with the administrative reform, the city administration systematically developed and evaluated its measurement and management practices. More recently, there has 
been a marked focus on knowledge management in an attempt to improve awareness and the ability of management to make decisions on the basis of the best possible information. As a part of this development process, an external auditor (a Finnish consultancy company) evaluated the maturity of the city's knowledge management in 2013. The auditor identified four main areas for development:

- An operating model for knowledge management is needed to ensure reliable and timely decision support

- A communication and training plan is needed (competence development)

- Harmonization of the technical architecture is required

- Recognition and modeling of service processes are needed

On the basis of the results of the external audit and the earlier unsatisfactory experiences of productivity and performance measurement programs, the city designated knowledge management as a strategic development area. The aim was to ensure the timely availability of reliable information for use in decision-making. Knowledge management was on the top-ten list of structural changes adopted by the City Executive Board for the period 2013-2016.

\subsection{Empirical Methods and Data}

The aim of the study was to better understand how knowledge management could support strategic public management and to explore whether and how a knowledge management strategy could improve the use of performance information. To achieve this, we examined one city using an action-oriented case study approach. We chose a case study approach to obtain detailed information on the conditions, critical events, and processes related to timely concerns in public management (Stake, 1994; Yin, 2009). We expected that a thorough understanding of the context would lead to generalizable findings and theoretical implications (e.g., Eisenhardt, 1989; Jensen and Rodgers, 2001; Stake, 1994).

We carried out action research (Clark 1972; Hult and Lennung, 1980) with participatory workshops and held several discussions with the person in charge of knowledge management in Tampere. This individual is also the second author of the paper, but during the action research process, she acted as an informant. We conducted the workshops in December 2013 and January 2014. We considered action research as an appropriate approach in this context because it concerned managerial processes and was aimed at deriving practice-related theoretical insights (Huxham and Vangen, 2003). The first author planned the workshops, but left plenty of opportunity for open dialogue, as one of the main aims was to build a shared 
understanding of knowledge management. The workshops lasted about three hours and were conducted in Finnish. The first author translated the quotations and the second author, as the city representative, checked their accuracy.

We arranged three workshops with two different groups. Each group had its own session, and after we analyzed the results, we arranged a combined session. The first group was the steering group for knowledge management in the City of Tampere (six persons). The second group was a specialist group of key actors (nine persons) responsible for the further development of knowledge management. The participants' professional positions ranged from administrative director and chief information officer to information specialist and development coordinator. Their expertise covered service management, administration, and information management. The participants had perspectives on knowledge management either as decisionmakers or information provider. Establishing a dialogue between the service line and technical expertise was considered essential. The primary data were complemented by strategic documents. The focus of the first workshop involving the steering group was the link between knowledge management and the city's strategic objectives. This discussion created a starting point for the second workshop, which focused on concrete steps for promoting and applying knowledge management in the city.

Each session began with an introduction by the first author (PowerPoint slides in English available on request). In the first two workshops, this presentation covered the basics of knowledge management and reviewed some recognized problems pointed out in the earlier maturity analysis (external audit). In the third, shared workshop, the presentation included a summary of the discussions of the two previous workshops and opened the discussion on issues remaining unresolved. The purpose of the presentations was to set the scene for the discussion. A third person (a researcher with a $\mathrm{PhD}$ in knowledge management) acted as secretary and took detailed notes while the first author led the discussion. Each session addressed three themes derived directly from the three objectives for the whole process: (1) arrive at a shared understanding of knowledge management in this particular context, (2) create an overall picture and rules for knowledge management within the city administration, and (3) specify future steps for knowledge management in the City of Tampere. The aim of this was to develop strategic knowledge management in the City of Tampere.

The researchers (both authors and the third researcher, who took the notes) held a reflective dialogue after each workshop to discuss the integrity of their interpretations and the main notions of the workshops. Triangulation increased the credibility and validity of the results. The notes were also double-checked by all three researchers. After the last workshop, the 
researchers drew on their notes to produce a final report on the whole process. To validate the findings and increase objectivity, this report was shared with the person in charge of the process in the city administration, and was subsequently made available to all workshop participants for checking and approval. Some minor corrections were made on the basis of the comments. The data gathered yielded a detailed description of the organization-specific knowledge management challenges and development needs. The primary data consisted of field notes and detailed documentation of the three development workshops. These data were complemented by three preliminary discussions and two follow-up discussions with the person in charge of the process in the City of Tampere. These discussions helped in planning the contents of the workshops and raised important aspects to support the analysis of the key findings.

\section{Empirical examination: a knowledge management strategy in the City of Tampere}

\subsection{Positioning Knowledge Management Strategically in the City of Tampere}

An organization's knowledge management strategy needs to reflect its competitive strategy and business vision (cf. Earl, 2001; Hansen, Nohria, and Tierney, 1999; Zack, 1999). The City of Tampere had not so far recognized a need for an overarching knowledge management strategy. Various knowledge-related development tasks had been accomplished, but the development work was fragmented over unrelated projects, and the overall picture was unclear. This observation emerged in preliminary discussions with city officials and was confirmed in the workshops. Thus, in the first workshop, a member of the steering group articulated the aims as follows:

Everyone comes to knowledge management from a different background. What we seek now is a shared view of the phenomenon. We want to create a knowledge-based management culture-one that builds on the shared vision of the city.

The lack of a clear knowledge management strategy appears to have inhibited internal and external communication. This was perceived in practice, and the results of the maturity analysis (the external audit) supported this observation. Thus, the steering group deemed it important to connect knowledge management and individual development initiatives or projects to a wider perspective and to the strategic objectives of the city administration. The steering group members believed that this would also facilitate communication by building a common language and knowledge culture (within the city administration). 


\subsection{Identifying Performance Gaps and Knowledge Needs}

The steering group members were unanimous on the ultimate aims: the main aim of all development initiatives is to improve the city’s performance. The steering group considered a broad definition of performance to ensure the productivity, efficiency, quality, and effectiveness of services. In order to make the knowledge agenda as concrete as possible, the overall aim was divided into three sub-categories: service provision, internal efficiency, and the prosperity of the area. The researchers proposed this categorization on the basis of the preliminary discussions. The steering group considered that each sub-objective improved the city's overall performance and that these encompass the existing strategic focal areas of the city administration (working together; enacting preventive measures and narrowing disparities in well-being, prosperity, and competitiveness; sustainable community; balanced finances; and innovation). The participants agreed with the use of different terminology here to keep the focus on knowledge issues without digressing into a strategic debate. Nevertheless, the city strategy was duly adhered to, and this proved to be a good starting point for the knowledge discussion. In this way, knowledge management became a core means of implementing the strategy.

After a shared understanding of the purpose of operations was reached, it was possible to proceed to a discussion on the decision support required. The next question concerned managerial knowledge needs: What information is needed to support decision-making to accomplish the objectives set? During the discussions with the steering group, some timely knowledge needs became evident. These knowledge needs represent the ongoing change in public management described earlier in the paper. The focus is shifting from internal efficiency to customer-perceived value and from organization-specific development to interorganizational and system-based value creation.

In practice, there is a need to scale the existing organization-specific productivity measures up to link them to the strategic objectives. A practical example of the change in managerial thinking can be found in home care. In addition to measuring home care as an organizational unit, the measurement should provide information on the success of the city administration in supporting elderly people to continue living in their own homes (a strategic objective). This represents a more general aim of capturing customer-perceived value- that is, effectiveness of services — which emphasizes collaboration and inter-organizational service chains. 


\subsection{Key Knowledge Management Actions}

During the process, two aspects of knowledge management actions were discussed. First, participants deemed it important to integrate knowledge management into other management systems. Second, they called for concrete steps to be determined through which the knowledge management strategy could be put into action.

The steering group members stressed that knowledge management should serve real knowledge needs, but at the time they found this link tenuous. The steering group concluded that without links to the city's basic tasks, information provision and indeed knowledge management more generally remained detached from everyday management. The steering group wanted to see a shift from project-based development to everyday practice. Change is needed at every level of local government. The steering group also stated that it was critical to build on the previous work on key indicators. The city government had previously invested great effort in the development of productivity measurement practices and had identified the management information needed and the management information already available. Now, all the work must be integrated, as a member of the steering group noted:

We need to complete the work. About 90 per cent has already been accomplished, but the most important part is still missing - the application of all the information available.

The group stressed the importance of connecting the existing data to the wider aims of service provision-that is, the strategic objectives. They underlined that the performance information should guide toward the management of cross-functional service provision and customer value. The information should also serve practical decision-making situations and support knowledge management more generally by building and promoting a culture of knowledge-based management. Here, it was underlined that all managers in the city have an important role-they need to apply management practices that utilize the best possible information. Results must be communicated and openly discussed in order to find new and better modes of operation. The steering group acknowledged that culture is slow to change and that change requires constant work and systematic management practices, in which performance information is put to use. In the final report to the City of Tampere (Finnish version available upon request from the City of Tampere), the authors articulated the need as follows: 
[W] hen building a knowledge-based management culture various negotiations for an agreement with service providers, team meetings and unit management groups etc. are situations where knowledge-based decision-making is put into practice. This is how the new culture is introduced. Simultaneously, it promotes performance-driven thinking and improves the situational awareness of the personnel.

From Strategy to Action. During the development process, the steering group identified four essential tasks as the main development areas in Tampere when putting the knowledge management strategy into practice: (1) identify the key indicators (derived from the strategy), (2) represent and model the concrete information need (management context), (3) analyze and present information, and (4) gather and refine information. These were recognized as essential tasks preceding and enabling decision-making and knowledge management more generally. The tasks may sound trivial, but in a complex environment such as local government, where the ideas of network management are gaining ground, forming a shared understanding of the tasks and responsibilities is not straightforward.

The transition from strategy to action gave rise to an important discussion on managers' information needs and information specialists' role in providing such information. Information specialists are concerned with issues like ensuring the reliability of the data and defining interfaces, roles, responsibilities, and tools for data processing. Service managers use information to make decisions that guide the organization towards its objectives. Currently, a clear juxtaposition between these viewpoints seems to prevail. Too often expectations regarding the interplay between information provision and strategic knowledge needs are not met and the knowledge management initiatives do not lead to strategic insights. Thus, a critical development task in knowledge management relates to improving the dialogue between the differing perspectives of information provision and service management. The participants conceded that work remained to be done on creating a common language and understanding between actors representing these views. The work described here-that is, developing a knowledge management strategy—is expected to act as a mediator, bringing the different views closer together.

Another practical concern related to refining and analyzing information, and thereby enhancing the quality and reliability of the data on which such information is based. The specialist group indicated that currently the quality of the data was not satisfactory. To remedy this, the city initiated a process for purchasing a master data management system. This was not 
considered merely as a technical process; it was also important to carefully design and implement rigorous processes to ensure quality in the future. Overall, a definition of key indicators was considered a starting point for better knowledge management. Focusing on these indicators is expected to clarify the management focus and provide a common language by defining key concepts and performance objectives. Moreover, participants expected this to help with resourcing and prioritization due to better information flow, which would further alleviate information overload from the viewpoint of individual employees.

\section{Identifying requirements for knowledge management in the public sector}

The recent literature on the use of performance information in the public sector stresses that there are other uses for performance information besides the direct link to decision-making. Pollitt (2006) points out a long-term enlightenment function and an imitative, symbolic, and cosmetic function. In addition, the existence of performance indicators legitimizes an administration as “modern” (Pollitt, 2006). Further, and even more importantly, Moynihan (2005) calls for an integrative dialogue. These perspectives turn the focus to the creation of premises for better decision-making and capacity building when the direct link between information and decision is missing (Nunn, 2007; Wiig, 2002). The collaborative nature of local government also creates a need for inter-organizational knowledge transfer and learning (Laihonen, 2015; Rashman, Downe, and Hartley, 2005; Rashman, Withers, and Hartley, 2009).

As one of the main outcomes of this study, the paper elaborates the evolving knowledge needs of public management during a transformation process from an internally focused management model to an open and customer-focused model (see Table 1). The table illustrates how the focus is shifting from internal efficiency to customer-perceived value. This requires new information in decision support, which calls for new performance goals and metrics. The development focus is also turning from individual organizations to horizontal service processes, meaning that the unit of analysis needs to be changed. Finally, the key knowledge management actions of public knowledge management are the improvement of interorganizational knowledge flows and collaborative processes where targets are defined and performance information is interpreted. Thus, the study provides a new perspective on public management by looking behind the various uses of performance information (e.g., Behn, 2003; Hammerschmid, Van de Walle, and Stimac, 2013; Moynihan, 2008) and factors affecting performance information use (e.g., Moynihan and Ingram, 2004; Moynihan and Pandey, 2010; Taylor, 2011). This was possible because, instead of choosing an external evaluation approach, 
the study applied a qualitative approach affording insights into the practice of public management during the transformation process.

$<<<<$ INSERT TABLE 1 HERE $>>>>>>$

The empirical examination of the development process, where a knowledge management strategy was developed in local government, yielded several valuable implications both for research and management practice. We believe that these implications will help in overcoming the reported challenges in implementing knowledge management in the public sector (cf. Liebowitz and Chen, 2003; Sveiby and Simons, 2002). Two main notions can be derived from this study.

First, the empirical data showed that it is not a straightforward process to move from an intra-organizational focus to inter-organizational and cross-functional collaboration in service provision. Here, it is important to maintain a strategic focus and concentrate on the creation of public value. This is also the essence of the knowledge management strategy and was set as a starting point in the City of Tampere, which helped to overcome the earlier criticism related to the over-emphasized technological perspective and extensive focus on certain functional areas (cf. Edge, 2005).

Nevertheless, the empirical examination demonstrated that much remains to be done in creating a common language between different actors. During the development process, the ambiguity of public management (Vakkuri, 2010) and cultural tensions (McGuire, 2006) were evident. The empirical data clearly illustrated the challenges of inter-organizational collaboration, where different organizational cultures, perceptions of the ongoing transformation, and individuals' mental models meet. It is also worth acknowledging individuals' disparate incentives for acquiring and using information (cf. Rajala, Laihonen and Vakkuri, 2017). These may have a significant impact on individuals' willingness to engage in the inter-organizational collaboration and learning that the new situation requires (Laihonen, 2015; Rashman, Withers, and Hartley, 2009). In its vision for 2025, the City of Tampere aims to tackle these challenges by focusing more on the cultural control mechanisms highlighting the culture of partnership and co-creation. The vision builds on three principles: personnel as developers, enabling management and a strong sense of community (City of Tampere, 2017.) Indeed, the city underlines the role of every employee as creators of Tampere and calls for joint efforts and working together across organizational boundaries. 
Developing a knowledge management strategy necessitates a careful analysis of the organization's mission and objectives. If these are not kept in mind, there is a danger that the knowledge management initiatives will become detached from everyday management, as was the case in the City of Tampere at the beginning of the project. When the overall aims are clear, it is possible to pose questions concerning the knowledge required. The case study demonstrated that implementing knowledge management in local government is not a straightforward process, and there seem to be very few readymade, universal solutions available. The study also showed that public knowledge management is definitely more than a technical manoeuver. In Tampere, the strategic approach provided practitioners with a new view and a conceptual toolbox that helped them to link the diverse set of objectives and the concrete knowledge management initiatives (Earl, 2001; Hansen, Nohria, and Tierney, 1999; Zack, 1999).

The practical recommendations and key elements of a knowledge management strategy in the public sector can be condensed into four critical success factors. The knowledge management strategy needs to be (1) steered by the city strategy and (2) tied to the general management system. The latter means that knowledge management should not be a separate function but embedded in everyday management activities. Further, the knowledge management strategy needs to (3) define processes and responsibilities for data gathering and refinement and (4) ensure data quality.

Second, related to all the above-listed elements, the critical success factor seems to be what we call "performance dialogue” (Laihonen and Mäntylä, 2017). From the empirical examination several areas emerged where the lack of a common language and discussion on the objectives and various interpretations of the ways to accomplish these can lead to misunderstandings. This may further lead to undesirable behavior, like sub-optimization or hoarding of knowledge. In a changing environment, it is especially important to pay attention to the social and organizational context in which performance information is to be used (cf. Behn, 2003; Moynihan, 2008; Vakkuri, 2010). Our findings support the literature proclaiming a need to focus more on learning and knowledge-generating aspects in strategic public management (e.g., Bryson et al., 2010; Moynihan, 2008; Rashman, Withers, and Hartley, 2009). From the knowledge management perspective, this means that it is not reasonable to push knowledge management as a ready-made solution and expect that it will solve the challenges not only in the use of performance information but also in public decision-making more generally. Although the current political climate in Finland advocates a highly rational approach, it is important to acknowledge the complexity of public decision-making and 
consider public knowledge management not as a decision-making machine but as a dialogue, where different information and viewpoints are discussed and interpreted (cf. Moynihan, 2005; Laihonen and Mäntylä, 2017).

This observation brings us to a discussion on the weaknesses of focusing solely on the decision-making side of knowledge management. This is, of course, a critical component in the public sector, where there is ample information available and where success depends heavily on the efficiency of decision-making. However, at the same time, the other side of the coin in public knowledge management is the recognition and building of the required knowledge assets to attain the sustainable development of society. This viewpoint has been stressed by Wiig (2002), who discusses building “competitive societal intellectual capital capabilities" and the role of "society's intellectual capital to improve the effectiveness of public and private decision making”. Anttiroiko (2008) continues on the same agenda and discusses strategic knowledge management in public organizations as "a set of theories and guidelines that provide tools for managing an organization's knowledge assets and processes of strategic importance". The viewpoint of knowledge assets becomes crucial in a changing environment where questions regarding the existing and needed knowledge assets determines the future success of the organization. Thus, when discussing strategic knowledge management in the public sector, it is important to keep in mind that it is a wider discussion than the current focus on decision-making and technological aspects would suggest. Therefore, we suggest that the discussion on strategic public knowledge management should carefully follow contributions in the area of intellectual capital management in public context (cf. Guthrie and Dumay, 2015).

For future research, the requirement for performance dialogue would mean that more qualitative research is needed on the management processes in which the information is used. Especially in complex situations, information use is often a collective effort, and the interesting phenomenon is actually the dialogue that takes place on the basis of the information provided. Further, this would mean that a knowledge management strategy should pay attention not only to information provision but also to the creation of organizational structures and platforms that would encourage and enable the evaluation of various interpretations. Furthermore, this raises a question, what are the knowledge assets and especially the individual capabilities that will be needed in the future? Answering this question definitely calls for a strategic discussion, and not only in the public sector.

\section{Conclusions}


This paper makes two contributions: first, by extending the analysis of knowledge management strategy to public management and, second, by providing a practical illustration of the development process, where knowledge was put into prime focus in developing public management. The study at hand applied an approach in an attempt to understand the various management aspects that must be taken into account when constructing a knowledge management strategy in local government. Thus, this paper links the theoretical discussions on knowledge and public management and provides a new understanding of public knowledge management.

Whereas the public management literature has extensively covered the characteristics of NPM and NPG, knowledge management takes a stand on the knowledge needed and carves a path from the existing knowledge base to a state where public organizations efficiently utilize their information and knowledge resources to achieve their goals. Furthermore, the knowledge management strategy defines the focus of knowledge management by describing responsibilities and setting limits and performance targets for all knowledge management initiatives. Especially during the transformation from NPM to NPG, this discussion seems to be of high relevance because the managers' knowledge needs are changing. This paper links knowledge management to city-level strategic objectives to reveal what the key elements of strategic knowledge management are at this level of local government.

To answer the research question, we suggest that four factors are critical to the success of strategic knowledge management in local government: strategic focus, integration of knowledge management in the management systems, refinement of the data, and quality of the data. Furthermore, the analysis of the empirical data revealed an increasing need for performance dialogue in local government. This focus on the actual use of performance information complements the often technocratic tradition of performance management, which focuses on indicators and information systems. In this study, it became evident that these need to be supported by cultural control mechanisms that encourage performance dialogue and lead to organizational learning. In addition, the dominant discussion seems to focus extensively on decision support, leaving a more profound discussion on the knowledge assets and capabilities needed in a subsidiary role. As a managerial implication, we argue that strategic knowledge management needs to balance the intertwined viewpoints of decision-making and knowledge assets in order to harness the full potential of knowledge management.

The issue of knowledge management in the public sector offers several avenues for future research. One of the most interesting and important questions relates to the implementation and operationalization of knowledge management as a part of the general management system and 
the creation of a culture of knowledge-based management. For example, some issues for future research to resolve are as follows: (1) How can we concretely build a management culture that relies on knowledge management and evidence-based decision-making? (2) What kinds of structures and management models encourage and support performance dialogue in local government? (3) What role do customers and citizens play in public knowledge management? (4) What knowledge assets are needed to better respond to and manage the burgeoning demand for public services?

The main limitation of the study is that it assessed only one case organization. Yet this is also a key strength of the study: Adopting an action-oriented approach made it possible to study the process of developing strategic knowledge management in a specific social and organizational setting. Despite its weaknesses, the results of the study highlight some of the cornerstones for developing a new kind of knowledge-based management culture in public organizations.

\section{References}

Alavi, M. and D. Leidner. (2001). "Review: Knowledge Management and Knowledge Management Systems: Conceptual Foundations and Research Issues.” MIS Quarterly, Vol. 25 No. 1, pp. 107-136.

Anttiroiko, A-V. (2008). Strategic Knowledge Management in Public Organizations. In: Murray E.J (Ed.), Knowledge Management: Concepts, Methodologies, Tools, and Applications, Vol. IV. Hershey, PA: IGI Global. pp. 2159-2167.

Behn, R. D. (2003). "Why Measure Performance? Different Purposes Require Different Measures.” Public Administration Review, Vol. 63 No. 5, pp. 586-606. doi:10.1111/1540-6210.00322.

Beynon-Davies, P. and S. Martin. (2004). "Electronic Local Government and the Modernisation Agenda: Progress and Prospects for Public Service Improvement." Local Government Studies, Vol. 30 No. 2, pp. 214-229. doi:10.1080/0300303042000267245.

Billis, D. (2010). Hybrid Organizations and the Third Sector. Challenges for Practice, Theory and Policy. Basingstoke: Palgrave MacMillan.

Bititci, U., P. Garengo, V. Dörfler, and S. Nudurupati. (2012). "Performance Measurement: Challenges for Tomorrow.” International Journal of Management Reviews, Vol. 14 No. 3, pp. 305-327.

Choi, B. and H. Lee. (2003). “An Empirical Investigation of Knowledge Management Styles and Their Effect on Corporate Performance.” Information and Management, Vol. 40 No. 5, pp. 403-417. doi:10.1016/S0378-7206(02)00060-5.

Choi, B., S. K. Poon, and J. G. Davis. (2008). "Effects of Knowledge Management Strategy on Organizational Performance: A Complementarity Theory-Based Approach.” Omega, Vol. 36 No. 2, pp. 235-251. doi:10.1016/j.omega.2006.06.007.

City of Tampere. (2014). Vuosikertomus 2014. Accessed 29 October 2015. http://www.tampere.fi/vuosikertomus/2014/index.html

Clark, P. A. (1972). Action Research and Organizational Change. London: Harper \& Row. 
City of Tampere (2017). Johtamisjärjestelmmän kuvaus [English title: Description of the management model]. Available:

http://www.tampere.fi/tiedostot/j/v1pygBEOp/Johtamisjarjestelman_kuvaus_PP_josta_ tehdaan_ulkoisten_nettisivujen_pdf.pdf. (Accessed: 21.8.2017)

Earl, M. (2001). “Knowledge Management Strategies: Toward a Taxonomy.” Journal of Management Information Systems, Vol. 18 No. 1, pp. 215-233. doi:10.1080/07421222.2001.11045670.

Edge, K. (2005). "Powerful Public Sector Knowledge Management: A School District Example.” Journal of Knowledge Management, Vol. 9 No. 6, pp. 42-52. doi:10.1108/13673270510629954.

Eisenhardt, K. M. (1989). "Building Theories from Case Study Research.” Academy of Management Review, Vol. 14 No. 4, pp. 532-550.

Grant, R. M. (1996). “Toward a Knowledge-Based Theory of the Firm.” Strategic Management Journal, Vol. 17, pp. 109-122.

Guthrie, J. and Dumay, J. (2015). "New frontiers in the use of intellectual capital in the public sector", Journal of Intellectual Capital, Vol. 16 No. 2, pp. 258-266, https://doi.org/10.1108/JIC-02-2015-0017.

Haggie, K. and J. Kingston. (2003). “Choosing Your Knowledge Management Strategy.” Journal of Knowledge Management Practice, Vol. 13, pp. 1-14.

Hakari, K. 2013. Uusi julkinen hallinta - kuntien hallinnonuudistusten kolmas aalto? Tutkimus Tampereen toimintamallista. Acta Universitatis Tamperensis 1871. Tampere University Press. Tampere.

Hammerschmid, G., S. Van de Walle, and V. Stimac. (2013). "Internal and External Use of Performance Information in Public Organizations: Results from an International Survey.” Public Money \& Management, Vol. 33 No. 4, pp. 261-268. doi:10.1080/09540962.2013.799803.

Hansen, M. T., N. Nohria, and T. Tierney. (1999). “What's Your Strategy for Managing Knowledge?” Harvard Business Review, March-April, pp. 106-116.

Hartley, J. (2005). “Innovation in Governance and Public Services: Past and Present.” Public Money and Management, Vol. 25 No. 1, pp. 27-34. doi:10.1111/j.14679302.2005.00447.x.

Haveri, A., I. Nyholm, A. Roiseland, and I. Vabo. (2009). “Governing Collaboration: Practices of Meta-Governance in Finnish and Norwegian Local Governments.” Local Government Studies, Vol. 35 No. 5, pp. 539-556. doi:10.1080/03003930903227360.

Hitt, M. A., R. D. Ireland, and H. Lee. (2000). “Technological Learning, Knowledge Management, Firm Growth and Performance: An Introductory Essay.” Journal of Engineering and Technology Management, Vol. 17 Nos. 3-4, pp. 231-246. doi:10.1016/S0923-4748(00)00024-2.

Hood, C. (1995). “The New Public Management in the 1980s: Variations on a Theme.” Accounting, Organizations and Society, Vol. 20 Nos. 2-3, pp. 93-109. doi:10.1016/0361-3682(93)E0001-W.

Hult, M. and S.-Å. Lennung. (1980). "Towards a Definition of Action Research: A Note and Bibliography.” Journal of Management Studies, Vol. 17 No. 2, pp. 241-250. doi:10.1111/j.1467-6486.1980.tb00087.x.

Huxham, C. and S. Vangen. (2003). "Researching Organizational Practice through Action Research: Case Studies and Design Choices.” Organizational Research Methods, Vol. 6 No. 3, pp. 383-403. doi:10.1177/1094428103254454.

Jensen, J. L. and R. Rodgers. (2001). "Cumulating the Intellectual Gold of Case Study Research.” Public Administrative Review, Vol. 61 No. 2, pp. 235-246. doi:10.1111/0033-3352.00025. 
Jääskeläinen, A. and H. Laihonen. (2014). “A Strategy Framework for Performance Measurement in the Public Sector.” Public Money \& Management, Vol. 34 No. 5, pp. 355-362. doi:10.1080/09540962.2014.945807.

Kalling, T. (2003). "Organization-Internal Transfer of Knowledge and the Role of Motivation: A Qualitative Case Study.” Knowledge and Process Management, Vol. 10 No. 2, pp. 115-126.

King, S. and Cotterill, S. (2007). "Transformational Government? The Role of Information Technology in Delivering Citizen-Centric Local Public Services.” Local Government Studies, Vol. 33 No. 3, pp. 333-354. doi:10.1080/03003930701289430.

Klijn, E.-H. (2008). "Governance and Governance Networks in Europe: An Assessment of Ten Years of Research on the Theme.” Public Management Review, Vol. 10 No. 4, pp. 505-525. doi:10.1080/14719030802263954.

Laihonen, H. (2012). “Knowledge Structures of a Health Ecosystem.” Journal of Health Organization and Management, Vol. 26 No. 4, pp. 542-558. doi:10.1108/14777261211251571.

Laihonen, H. (2015). “A Managerial View of the Knowledge Flows of a Health-Care System.” Knowledge Management Research \& Practice, Vol. 13 No. 4, pp. 475-485. doi:10.1057/kmrp.2014.3.

Laihonen, H. and Mäntylä, S. (2017), "Principles of performance dialogue in public administration”, International Journal of Public Sector Management, Vol. 30No. 5, pp. 1-16.

Laihonen, H., A. Jääskeläinen, and S. Pekkola. (2014). "Measuring Performance of a Service System - From Organizations to Customer-Perceived Performance.” Measuring Business Excellence, Vol. 18 No. 3, pp. 73-86. doi:10.1108/MBE-08-2013-0045.

Laihonen, H., A. Lönnqvist, and J. Metsälä. (2015). “Two Knowledge Perspectives to Growth Management.” VINE: Special Issue on Knowledge Strategies, Vol. 45 No. 4, pp. 473-494.

Lönnqvist, A. and H. Laihonen. (2012). "Welfare Service System Productivity: The Concept and Its Application.” International Journal of Productivity and Performance Management, Vol. 61 No. 2, pp. 128-141.

Liebowitz, J. and Y. Chen. (2003). "Knowledge-Sharing Proficiencies: The Key to Knowledge Management.” In Handbook on Knowledge Management 1: Knowledge Matters, edited by C. W. Holsapple, pp. 409-424. Berlin: Springer-Verlag.

Luen, T. W. and S. Al-Hawamdeh. (2001). "Knowledge Management in the Public Sector: Principles and Practices in Police Work.” Journal of Information Science, Vol. 27 No. 5, pp. 311-318. doi:10.1177/016555150102700502.

McGuire, M. (2006). "Collaborative Public Management: Assessing What We Know and How We Know It.” Public Administration Review, Vol. 66, no. s1, pp. 33-43.

Ministry of Finance. (2016). "Government Decision on Next Steps in Reform Package on Healthcare, Social Welfare and Autonomous Regions.” Accessed 20 May 2016. http://vm.fi/en/article/-/asset_publisher/10616/hallitus-paatti-sote-uudistuksenjatkosta-ja-itsehallintoalueista.

Moynihan, D. P. (2005). "Goal-Based Learning and the Future of Performance Management.” Public Administration Review, Vol. 65 No. 2, pp. 203-216. doi:10.1111/j.1540-6210.2005.00445.x.

Moynihan, D. P. (2008). The Dynamics of Performance Management: Constructing Information and Reform. Washington, DC: Georgetown University Press.

Moynihan, D. P. and P. W. Ingraham. (2004). "Integrative Leadership in the Public Sector: A Model of Performance-Information Use.” Administration \& Society, Vol. 36 No. 4, pp. 427-453. doi:10.1177/0095399704266748. 
Moynihan, D. P. and N. Landuyt. (2009). "How Do Public Organizations Learn? Bridging Cultural and Structural Perspectives.” Public Administration Review, Vol. 69 No. 6, pp. 1097-1105.

Moynihan, D. P. and S. K. Pandey. (2010). “The Big Question for Performance Management: Why Do Managers Use Performance Information?” Journal of Public Administration Research and Theory, Vol. 20 No. 4, pp. 849-866. doi:10.1093/jopart/muq004.

Nemec, J. (2013). "Public Sector Reform: An Overview of Recent Literature and Research on NPM and Alternative Paths.” International Journal of Public Sector Management, Vol. 26 No. 1, pp. 4-16.

Nunn, A. (2007). “The Capacity Building Programme for English Local Government: Evaluating Mechanisms for Delivering Improvement Support to Local Authorities.” Local Government Studies, Vol. 33 No. 3, pp. 465-484. doi:10.1080/03003930701289703.

Osborne, S. P. (2006). “The New Public Governance?” Public Management Review, Vol. 8 No. 3, pp. 377-387. doi:10.1080/14719030600853022.

Peters, G. B. (2011). “Comparative Public Administration: After New Management, What?” In Julkinen hallinto ja julkinen johtaminen, edited by E. Hyyryläinen and O.-P. Viinamäki, pp. 20-32. Vaasa: Acta Wasaensia.

Pollitt, C. (2006). "Performance Information for Democracy: The Missing Link?” Evaluation, Vol. 12 No. 1, pp. 38-55. doi:10.1177/1356389006064191.

Pollitt, C. and H. Summa. (1997). "Trajectories of Reform: Public Management Change in Four Countries.” Public Money \& Management, Vol. 17 No. 1, pp. 7-18. doi:10.1111/1467-9302.00051.

Pollitt, C., S. van Thiel, and V. Homburg. (2007). New Public Management in Europe: Adaptation and Alternatives. Basingstoke: Palgrave Macmillan.

Rajala, T., Laihonen, H. and Vakkuri, J. (2017). "Shifting from Output to Outcome Measurement in Public Administration - Arguments Revisited”. In Borgonovi, E., Pessina, E.A. and Bianchi, G. (Ed.) Outcome-Based Performance Management in the Public Sector, pp. 2-23. Springer.

Rashman, L., J. Downe, and J. Hartley. (2005). "Knowledge Creation and Transfer in the Beacon Scheme: Improving Services Through Sharing Good Practice.” Local Government Studies, Vol. 31 No. 5, pp. 683-700. doi:10.1080/03003930500293732.

Rashman, L., E. Withers, and J. Hartley. (2009). "Organizational Learning and Knowledge in Public Service Organizations: A Systematic Review of the Literature.” International Journal of Management Reviews, Vol. 11 No. 4, pp. 463-494. doi:10.1111/j.14682370.2009.00257.x.

Salamon, L. M. (2002). The Tools of Government: A Guide to the New Governance. Oxford: Oxford University Press.

Salojärvi, S., P. Furu, and K.-E. Sveiby, (2005). "Knowledge Management and Growth in Finnish SMEs.” Journal of Knowledge Management, Vol. 9 No. 2, pp. 103-122. doi:/10.1108/13673270510590254.

Sanderson, I. (2001). "Performance Management, Evaluation and Learning in Modern Local Government.” Public Administration, Vol. 79 No. 2, pp. 297-313. doi:10.1111/14679299.00257.

Soliman, F. and K. Spooner. (2000). "Strategies for Implementing Knowledge Management: Role of Human Resources Management.” Journal of Knowledge Management, Vol. 4 No. 4, pp. 337-345. doi:10.1108/13673270010379894.

Spender, J. C. (1996). "Making Knowledge the Basis of a dynamic theory of the firm." Strategic Management Journal, Vol. 17, pp. 45-62. 
Stake, R. E. (1994). “Case Studies.” In Handbook of Qualitative Research, edited by Denzin N. K. and Y. S. Lincoln, pp. 236-247. Thousand Oaks: Sage.

Sveiby, K. and R. Simons. (2002). "Collaborative Climate and Effectiveness of Knowledge Work: An Empirical Study.” Journal of Knowledge Management, Vol. 6 No. 5, pp. 420-433. doi:10.1108/13673270210450388.

Syysnummi, P. and H. Laihonen. (2014). “Top Management’s Perception of Knowledge Management in a Vocational Education and Training Organization in Finland.” International Journal of Educational Management, Vol. 28 No. 1, pp. 53-65. doi:10.1108/IJEM-04-2013-0067.

Taylor, J. (2011). "Factors Influencing the Use of Performance Information for DecisionMaking in Australian State Agencies.” Public Administration., Vol. 89 No. 4, pp. 1316-1334. doi:10.1111/j.1467-9299.2011.02008.x.

Vakkuri, J. (2010). "Struggling with Ambiguity: Public Managers as Users of NPM-Oriented Management Instruments.” Public Administration, Vol. 88 No. 4, pp. 999-1024. doi:10.1111/j.1467-9299.2010.01856.x.

van Beveren, J. (2003). “Does Health Care for Knowledge Management?” Journal of Knowledge Management, Vol. 7 No. 1, pp. 90-95. doi:10.1108/13673270310463644.

van Helden, G. J., Å. Johnsen, and J. Vakkuri. (2008). "Distinctive Research Patterns in Public Sector Performance Measurement of Public Administration and Accounting Disciplines.” Public Management Review, Vol. 10 No. 5, pp. 641-651. doi:10.1080/14719030802264366.

Van Dooren, W. and S. Van de Walle. (2008). Performance Information in the Public Sector: How It Is Used? Basingstoke: Palgrave.

Von Krogh, G. (1998). “Care in Knowledge Creation.” California Management Review, Vol. 40 No. 3, pp. 133-153.

Wiig, K. M. (2002). “Knowledge Management in Public Administration.” Journal of Knowledge Management, Vol. 6 No. 3, pp. 224-239. doi:10.1108/13673270210434331.

Yang, J. (2010). “The Knowledge Management Strategy and Its Effect on Firm Performance: A Contingency Analysis.” International Journal of Production Economics, Vol. 125 No. 2, pp. 215-223. doi:10.1016/j.ijpe.2010.03.012.

Yin, R. K. (2009). Case Study Research - Design and Methods. Thousand Oaks: Sage.

Zack, M. (1999). "Developing a Knowledge Strategy.” California Management Review, Vol. 41 No. 3, pp. 125-145. doi:10.2307/41166000. 
Table 1. Evolving requirements for knowledge management in the public sector

\begin{tabular}{|c|c|c|}
\hline $\begin{array}{l}\text { Component of a } \\
\text { knowledge } \\
\text { management strategy }\end{array}$ & $\begin{array}{l}\text { Requirements for knowledge } \\
\text { management in NPM }\end{array}$ & $\begin{array}{l}\text { Requirements for knowledge } \\
\text { management in NPG }\end{array}$ \\
\hline $\begin{array}{l}\text { Main focus (Business } \\
\text { vision) }\end{array}$ & $\begin{array}{ll}\text { - } & \text { Management by results } \\
\text { (internal efficiency) }\end{array}$ & $\begin{array}{ll}\text { Customer-perceived value } \\
\text { (effectiveness of services) }\end{array}$ \\
\hline $\begin{array}{l}\text { How to improve? } \\
\text { (Performance gaps) }\end{array}$ & $\begin{array}{l}\text { Improve efficiency of } \\
\text { service organizations }\end{array}$ & - Improve horizontal cooperation \\
\hline $\begin{array}{l}\text { What information is } \\
\text { needed in decision- } \\
\text { making? (Knowledge } \\
\text { gap) }\end{array}$ & $\begin{array}{l}\text { - Information about } \\
\text { internal efficiency }\end{array}$ & $\begin{array}{ll}\text { - } & \text { Information about effectiveness of } \\
\text { services } \\
\text { - } & \text { Information about network } \\
\text { performance }\end{array}$ \\
\hline $\begin{array}{l}\text { Key knowledge } \\
\text { management actions } \\
\text { (Knowledge } \\
\text { initiatives) }\end{array}$ & $\begin{array}{l}\text { - Improve internal } \\
\text { information flow } \\
\text { - Organizational target } \\
\text { setting }\end{array}$ & $\begin{array}{l}\text { - Improve inter-organizational } \\
\text { information flow } \\
\text { - Discussion and definition of shared } \\
\text { targets }\end{array}$ \\
\hline
\end{tabular}

